
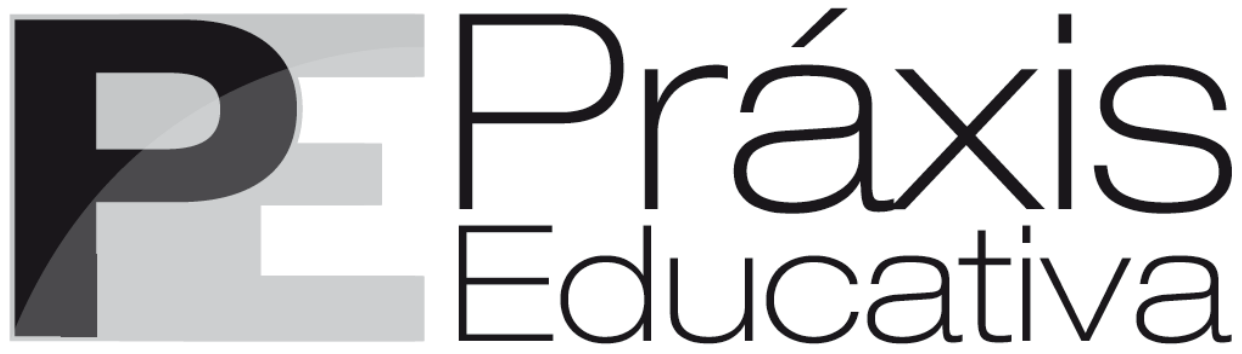

ISSN 1809-4031

elSSN 1809-4309

https://doi.org/10.5212/PraxEduc.v.15.14804.029

\title{
O diálogo e a aprendizagem com Tecnologias da Informação e Comunicação no homeschooling
}

\section{Dialogue and learning with Information and Communication Technologies in homeschooling}

\author{
Diálogo y el aprendizaje con Tecnologías de la Información \\ y Comunicación en homeschooling \\ Renato de Oliveira Brito \\ iD https://orcid.org/0000-0002-9345-2529 \\ Luiz Síveres ${ }^{* *}$ \\ iD http:/ / orcid.org/0000-0003-4735-6066 \\ Luís Paulo Leopoldo Mercado*** \\ iD http://orcid.org/0000-0001-8491-6152 \\ Idalberto José das Neves Júnior ${ }^{* * * *}$ \\ https://orcid.org/0000-0002-2241-9756
}

Resumo: Este artigo tem como objetivo caracterizar o homeschooling, de modo a identificar as contribuições das Tecnologias da Informação e Comunicação (TIC) na educação domiciliar no desenvolvimento de competências dialógicas na formação dos educandos e pais que vivenciam o bomeschooling. Realizou-se pesquisa de campo por meio de entrevistas, no período de setembro a outubro de 2019, com cinco famílias que praticam o bomeschooling nas cidades de Brasília e Rio de Janeiro. Os resultados evidenciaram que as famílias entrevistadas têm a prática do homeschooling, em média, de 12,6 anos; que a educação individualizada, a flexibilidade para avançar e individualizar a aprendizagem são razões de escolha pela educação domiciliar;

\footnotetext{
* Doutor em Educação pela Universidade Católica de Brasília (UCB). Docente/Pesquisador Permanente da UCB. Email:<renatoorios@gmail.com>.

** Doutor em Desenvolvimento Sustentável pela Universidade de Brasília (UCB). Docente/Pesquisador Permanente da UCB. E-mail: <luiz.siveres@gmail.com>.

*** Doutor em Educação pela Pontifícia Universidade Católica de São Paulo. Professor Titular da Universidade Federal de Alagoas. E-mail: <luispaulomercado@gmail.com>.

**** Doutor em Educação pela Universidade Católica de Brasília (UCB). Docente da UCB. E-mail: <idalbertoneves@gmail.com>.
} 
que o diálogo é praticado de forma ampla, ocorrendo em todos os espaços de aprendizagem; e que as TIC, como as redes sociais, as plataformas educativas, os livros digitais e as aulas online têm sido utilizadas no homeschooling. $\mathrm{O}$ estudo permitiu concluir que o diálogo e as TIC são instrumentos que ampliam as possibilidades de aprendizagem das crianças e dos adolescentes homeschoolers.

Palavras-chave: Ensino Domiciliar. Homeschooling. TIC. Diálogo.

Abstract: This paper aims to characterize homeschooling in order to identify the contributions of Information and Communication Technologies (ICT) in home education in the development of dialogic skills in the education of students and parents who experience homeschooling. Field research was conducted through interviews from September to October 2019 to five families who practice homeschooling in the cities of Brasília and Rio de Janeiro, Brazil. The results showed that the interviewed families had, on average, 12.6 years of homeschooling practice; that individualized education, flexibility to advance and individualize learning are reasons for choosing home education; that dialog is widely practiced, occurring in all learning spaces; and that ICT, such as social networks, educational platforms, digital books and online classes have been used in homeschooling. The study allowed to conclude that dialog and ICT are instruments that expand the learning possibilities of homeschooler children and adolescents.

Keywords: Home education. Homeschooling. ICT. Dialog.

Resumen: Este artículo tiene como objetivo caracterizar el homeschooling, de modo a identificar las contribuciones de las tecnologías de la información y comunicación (TIC) en la educación domiciliaria en el desarrollo de competencias dialógicas en la formación de los estudiantes y padres que vivencian el bomeschooling. Se realizó investigación de campo por medio de entrevistas en el período de septiembre a octubre de 2019 a cinco familias que practican bomeschooling en las ciudades de Brasilia y Río de Janeiro. Los resultados mostraron que las familias entrevistadas tienen la práctica de homeschooling, en promedio, 12,6 años; que la educación individualizada, la flexibilidad para avanzar e individualizar el aprendizaje son razones de elección para la educación en el hogar; que el diálogo es practicado de forma amplia, ocurriendo en todos los espacios de aprendizaje; y que las TIC, como las redes sociales, las plataformas educativas, los libros digitales y las clases en línea se han utilizado en el homeschooling. El estudio permitió concluir que el diálogo y las TIC son instrumentos que amplían las posibilidades de aprendizaje de los niños y adolescentes bomeschoolers.

Palabras clave: Enseñanza Domiciliaria. Homeschooling. TIC. Diálogo.

\section{Introdução}

O homeschooling, ou educação domiciliar, ou educação em casa, como é conhecida no Brasil, é uma modalidade de educação que acontece no âmbito privado na casa da família, na qual crianças e adolescentes são formados e orientados, geralmente, pelos adultos daquele núcleo familiar. "Nela a família se responsabiliza totalmente pela formação acadêmica da criança, mobilizando pais ou tutores, diversas estratégias que podem seguir ou não um currículo formal" (BARBOSA; EVANGELISTA, 2017). Assim sendo, a casa com todos os seus espaços caracteriza-se em um ambiente de aprendizagem e, com todas as dinâmicas, familiares buscam contribuir com uma formação mais integral e integradora.

Os pais ou responsáveis dessas crianças e adolescentes pleiteiam e justificam a escolha pela educação domiciliar, indicando liberdade de escolha dos pais, motivações religiosas, convicções e valores familiares, preservação das crianças de assédio moral ou bullying, insatisfação com as escolas ou até mesmo a crença de que educação domiciliar pode ser melhor que a educação escolar (SEMIS, 2019; CURY, 2019; BARBOSA, 2016; BARBOSA; EVANGELISTA, 2017; NOVAES et al., 2017; PICOLI, 2020). São José (2014) destaca que os motivos que levam as famílias brasileiras a optarem pelo ensino domiciliar variam e, entre eles, estão valores religiosos, flexibilidade dos horários, liberdade em optar por um currículo diferenciado, prosseguir ou retrosseguir no aprendizado de acordo com as possibilidades e as necessidades do educando.

Práxis Educativa, Ponta Grossa, v. 15, e2014804, p. 1-21, 2020 Disponível em: <https://www.revistas2.uepg.br/index.php/praxiseducativa> 
É com essas justificativas que os números da educação domiciliar vêm crescendo no mundo. Nos Estados Unidos, estima-se que 2,04 milhões de crianças estejam sendo educadas em casa, considerada a maior população de homeschooled de que se tem informação (VIEIRA, 2012). No estado australiano de Nova Gales do Sul, o mais populoso do país, estima-se que a expansão do número de educandos domiciliares, entre 2003 e 2009, tenha sido de cerca de 60\%, passando de 1,4 mil para 2,3 mil registrados no Board of Studies (VIEIRA, 2012). Esses dados são confirmados por Kunzman (2012) ao indicar a estimativa de 74\% dos homeschooler nos EUA no período de 1999 a 2007.

No Brasil, de acordo com a Global Home Education Conference (GHEC, 2016) existe 4.200 famílias adeptas à essa modalidade educativa. A previsão é de que existam 17.214 educandos, em regime de Educação Domiciliar, até o ano de 2020, indicando um crescimento significativo quando comparado ao número realizado em 2011, quando havia 358 educandos, segundo a pesquisa da Associação Nacional de Ensino Domiciliar (ANED, 2019). Esses dados evidenciam números crescentes de famílias que optam pela educação domiciliar, indicando, de forma legítima e democrática, que as escolhas dos pais de crianças e adolescentes por essa modalidade educativa, nem sempre são acompanhadas por uma legislação que regule essa Educação, a exemplo do que ocorre no Brasil, embora, de acordo com os argumentos de Davies e Aurini (2003), a liberdade individual de consciência, do direito à vida e à liberdade estão baseadas no art. 26 da Declaração Universal dos Direitos Humanos, que assegura o direito preferencial aos pais para escolher o tipo de educação que será dado aos filhos.

A legislação brasileira não proíbe explicitamente a educação domiciliar e, também, não a respalda. A Lei de Diretrizes e Bases da Educação Nacional (LDBEN) - Lei No 9.394, de 20 de dezembro de 1996 - prevê que é dever dos pais ou responsáveis a matrícula das crianças, a partir dos quatro anos de idade, na Educação Básica (BRASIL, 1996). O Código Penal Brasileiro criminaliza os pais ou responsáveis pelo não atendimento da LDBEN. O Supremo Tribunal Federal (STF) julgou que a educação domiciliar não deveria ser admitida, enquanto não houver regulamentação, embora o atual governo deixe explícito que a educação domiciliar é uma das pautas prioritárias de sua gestão (ANDRADE, 2017; SEMIS, 2019; AGUIAR, 2011; COSTA, 2016).

Nesse cenário, o contexto brasileiro de regulamentação da educação domiciliar parece indicar para uma possibilidade de resolução legal, fato que poderia corroborar com a adesão crescente das famílias, mundo afora, a exemplo dos Estados Unidos, Austrália e Brasil, pela educação de crianças e de adolescentes em casa. Exemplo disso são as propostas de regulamentação do bomeschooling que estão tramitando no Congresso Nacional, que visam garantir o direito individual de liberdade de escolha da educação pelas famílias no âmbito privado, alterando a Lei $\mathrm{N}^{\circ} 9.394 / 1996$ (LDBEN) e a Lei $\mathrm{N}^{\circ}$ 8.069/1990 (ECA), ampliando os deveres do Estado e da família em relação à educação.

As propostas preveem o desenvolvimento da Educação Básica obrigatória, sob a orientação dos pais ou responsáveis, mediante autorização específica e supervisão do respectivo sistema de ensino (BRASIL, 2017), sendo garantido o cumprimento da Base Nacional Comum Curricular (BNCC), a avaliação de rendimentos periódicos, por meio de exames nacionais, acompanhamento e fiscalização do poder público.

Esse modelo de educação é concebido em processos educativos que apresentam os próprios familiares ou grupos de pais e outros responsáveis na tutoria de aprendizagem das crianças e dos adolescentes, podendo ter a contratação de professores particulares para a realização das atividades de tutoria da aprendizagem em casa. É possível a utilização de materiais e conteúdos programáticos das escolas regulares para o estudo domiciliar, havendo, inclusive, a possibilidade desses tutores não abordarem todos os conteúdos trabalhados na escola (SEMIS, 2019). Entre essas características, um fator importante que deve ser considerado, para uma possível consolidação da educação domiciliar, é o valor financeiro para custear uma educação de crianças ou de 
adolescentes em casa, o que, de certa forma, pode desvelar uma taxa de crescimento dos números de educandos em famílias de padrão superior de poder aquisitivo. No caso do Brasil, onde há uma grande concentração de baixa renda, questiona-se até que ponto os pais com baixos salários poderiam custear a educação domiciliar.

Uma outra vertente a ser explorada é como os processos educativos da educação domiciliar são conduzidos e mediados. Fatos curiosos a serem estudados seriam: como o diálogo e as TIC estão presentes nessa modalidade? O diálogo, como artefato de comunicação, impacta os processos de ensino-aprendizagem, a relação professor-educando e a própria educação (NEVES JÚNIOR, 2018)? As TIC, usadas como recursos tecnológicos, suportam os processos de ensinoaprendizagem, utilizadas de forma integrada e favorecem uma educação que permita a reflexão e a aprendizagem dos educandos?

O pressuposto deste artigo está ancorado em processos de ensino e de aprendizagem, mediados pelo diálogo e as TIC, que podem favorecer a atribuição de sentido e de significado para os educandos. Com esse pressuposto, neste artigo, pretende-se responder como o diálogo é efetivado e como as TIC estariam sendo utilizadas na educação domiciliar, considerando que são mediações importantes e necessárias para o desenvolvimento de uma aprendizagem significativa. A contribuição deste texto está em permitir uma reflexão sobre a importância e a efetividade do diálogo e das TIC, nos processos de ensino e de aprendizagem na educação domiciliar, resultando em possibilidades formativas que estariam à disposição das famílias e dos tutores para que o processo formativo de crianças e de adolescentes, realizado em casa, possa ser de qualidade e de pleno de sentido para todos os envolvidos nesse procedimento educacional.

\section{Homeschooling como possibilidade de educação aberta: as contribuições das TIC}

De acordo com Andrade (2014), o termo bomeschooling é usado internacionalmente para identificar uma modalidade de educação específica organizada e implementada pelos próprios pais como alternativa de escolarização de seus filhos em casa e não na escola, cenário que se amplia cada vez mais com as possibilidades trazidas pela educação online e educação aberta. Nesse sentido, um dos principais benefícios do homeschooling é a habilidade de adaptar a educação de acordo com as necessidades de cada educando e a possibilidade de trabalhar com a criança de forma mais individualizada. Além disso, fornece aos pais a habilidade de customizar um meio de aprendizado para cada criança (DUMAS; GATES; SCHWARZER, 2010).

O Decreto $N^{\circ}$ 5.622, de 19 de dezembro de 2005, no seu art. 30, que regulamentava a Educação a Distância $(\mathrm{EaD})$ e englobava a educação online, estabelecia condições para situações emergenciais no Ensino Fundamental e Médio (BRASIL, 2005). Ele foi revogado pelo Decreto $\mathrm{N}^{\circ}$ 9.057, de 25 de maio de 2017, o qual, em seus artigos $8^{\circ}$ e $9^{\circ}$, mantém as condições anteriores, mas flexibilizam a oferta da modalidade (BRASIL, 2017). O documento permite condicionalidades "[...] ligadas à saúde, as relativas a pessoas no exterior, às pessoas no exterior, as pessoas cujas localidades 'não possuam rede regular de atendimento escolar presencial' ou estejam em regiões de difícil acesso e aos que estejam privados de liberdade” (CURY, 2019, p. 5). O Decreto No 9.057/2017 não se refere à homeschooling, mas há alternativa pela $\mathrm{EaD}$, que oferece inúmeras possibilidades no contexto da educação aberta e educação domiciliar: educação online, ensino híbrido, sala de aula invertida, Massive Open Online Courses (MOOC) - cursos abertos massivos online, sequências didáticas elaboradas sob medida para a aprendizagem individualizada e autônoma.

Barbosa (2013) menciona várias motivações apresentadas pelas famílias ao optar pela educação domiciliar, constatando um discurso cada vez mais crescente em favor de um ensino mais individualizado, voltado a melhor atender às características e às necessidades dos educandos.

Práxis Educativa, Ponta Grossa, v. 15, e2014804, p. 1-21, 2020 Disponível em: < https://www.revistas2.uepg.br/index.php/praxiseducativa> 
Vasconcelos (2015, p. 12) ratifica que a “[...] a educação doméstica constitui uma das formas de educação alternativa a que as famílias, sob a influência de condições específicas, recorrem quando, entre outros motivos, a escola não alcança as expectativas de suas demandas".

Em relação à metodologia trabalhada na educação domiciliar, Barbosa (2013) aponta que, no que diz respeito aos pais homeschoolers, que se veem como "escolhedores" entre uma variedade de métodos, sendo a tendência o uso de vários até encontrar a melhor maneira do educando aprender. Para Andrade (2014), a característica mais relevante valorizada pelos homeschoolers é a capacidade de ser autodidata, ou seja, aprender de forma autônoma. O autor afirma que é a capacidade de aprender por meio de um processo que valoriza a autoaprendizagem, sem a necessidade de um professor/tutor ou preceptor.

Nos contextos de aprendizagem aberta, que vão além dos espaços formais, o homeschooling exige novas formas de ensinar e aprender e as TIC oferecem novos cenários para essa aprendizagem (PÉREZ GÓMEZ, 2015; COLL; MONEREO, 2010). Isso permite o ensino personalizado com a individualização dos percursos pessoais de aprendizagem, flexibilização da aprendizagem e investimentos em inovações tecnológicas na área diante da ubiquidade, capacidade de estar ao mesmo tempo em lugares diferentes.

$\mathrm{Na}$ aprendizagem personalizada, a individualização do ensino propicia um acompanhamento constante e contribui para a formação de grupos capazes de gerar mais aprendizados. É uma sala de aula sem fronteiras, em que novos conhecimentos chegam aos educandos respeitando o tempo de aprender de cada um. É possível verificar o crescimento de uma oferta de ensino diferenciado e individualizado, lógica na qual se insere o bomeschooling (AURINI; DAVIES, 2005). As dificuldades estão no apoio que vem por meio de intervenção que auxilia o educando a superar os desafios da aprendizagem ou redireciona o caminho do aprendizado, tentando encontrar a abordagem mais adequada para a construção do conhecimento.

A aprendizagem personalizada demanda a oferta de serviços educativos em forma ubíqua. As TIC facilitam o acesso e a distribuição dos conteúdos online e a interação entre os envolvidos. Envolve a autonomia em rede, na qual a escola é substituída por uma rede global de educação, com provedores de conteúdos e agentes educativos (tutores e preceptores) e entidades certificadoras que asseguram o cumprimento das normativas e das diretrizes educativas internacionais, nacionais e locais.

De acordo com a Fundación Telefónica (2012, p. xiv), os educandos, junto a seus pais, escolhem a entidade certificadora e os recursos da rede global de educação, e um guia os orienta. É promovida a interação de educandos em comunidades fechadas que compartem objetivos e métodos de aprendizagem e os agentes educativos. O modelo prioriza que os educandos aprendam a aprender e as tecnologias chave são as de mercados virtuais de serviços e curadoria inteligente de recursos e de conteúdos.

Ferramentas de Inteligência Artificial (IA) permitem ampliar a inteligência humana, por meio do uso de tutores inteligentes (algoritmos) que ensinam as TIC a lidar com informação proveniente do conteúdo que será ensinado, do modo como ele será ensinado e conhecimentos que o educando já possui. Estudos têm sido realizados a fim de ampliar a compreensão sobre o comportamento dos educandos durante a aprendizagem (NEW MEDIA CONSORTIUM, 2013; MONEREO; POZO, 2010; HARASIM et al., 2005), os quais utilizam interfaces capazes de reconhecer palavras, captar gestos, verificar o movimento dos olhos e de diversos indicadores fisiológicos (batimentos cardíacos e tensão muscular).

A aprendizagem autônoma, segundo Moraes (1997),

Práxis Educativa, Ponta Grossa, v. 15, e2014804, p. 1-21, 2020 
[...] pressupõe a busca de informações onde quer que elas estejam pelo domínio de diferentes formas de acesso à informação associado ao desenvolvimento de uma atitude crítica de investigação, no sentido de que o indivíduo seja capaz de avaliar, reunir e organizar as informações mais relevantes [...]. O desenvolvimento da criticidade facilita a identificação da fonte de produção da informação, a análise de sua validade e a possibilidade de compará-la, decidindo qual será mais útil para o desenvolvimento do seu trabalho. [...]. O aprendizado autônomo pressupõe flexibilidade, facilidade para mudar valores, para promover diálogos e habilidades de comunicação no que se refere à cooperação, à coordenação e à decisão decorrentes das vivências de trabalhos em grupo na procura de soluções conjuntas para os problemas. (MORAES, 1997, p. 223-224).

A aprendizagem autônoma permite ao educando a busca de informações na internet, de forma flexível e crítica, sem estar preso a roteiros definidos ou a sites já escolhidos previamente. $\mathrm{O}$ educando tem liberdade de escolha na sua navegação. Outro aspecto é a flexibilidade cognitiva, conceito construtivista aplicado ao uso da internet por Jonassen (1997) quando afirma que, no processo de conciliar múltiplas perspectivas de casos autênticos, os educandos devem construir sua própria interpretação da verdade, em vez de instrutores transmitindo conhecimento objetivo e exigindo que aprendizes codifiquem essas representações do conhecimento para adaptá-las e usálas em novas situações. Assim sendo, estratégias e ferramentas tecnológicas usadas na educação online em Ambientes Virtuais de Aprendizagem (AVA) podem perfeitamente servir como contexto da homeschooling.

A concepção de um único lugar como centro formativo e instrutivo tende a desaparecer e, com a internet, os espaços do conhecimento e da aprendizagem ampliam-se e vão desde o recinto escolar à administração pública, às empresas privadas e ao espaço doméstico, o que facilita, amplia e flexibiliza os lugares de trabalho do educando, permitindo uma versatilidade no tempo para a instrução e a aprendizagem. Isso propicia ao educando determinar ativamente os momentos temporais que deseja destinar a instrução, já que o mundo comunicativo das redes se encontra sempre aberto e disponível, se a cobertura técnica o permite para sua imersão e navegação.

A aula online permite uma formação mais individualizada e flexível, nas quais é possível contemplar as possibilidades e as características do sujeito que aprende, seu ritmo de aprendizagem e sua disponibilidade horária. $\mathrm{Na}$ educação online, os educandos podem organizar suas atividades formativas em ritmo conveniente para eles, com independência do lugar no qual se dá a aprendizagem. As TIC podem facilitar o acesso ou a distribuição do material didático aos educandos assim como a interação entre professor/tutor/preceptor e educando no momento mais conveniente para eles (interação assíncrona).

A aprendizagem na educação online envolve a capacidade de as pessoas relacionarem as informações de maneira crítica em uma perspectiva globalizada e centrada na resolução de problemas significativos, no qual o conhecimento é visto como instrumento para compreensão e possível intervenção da realidade. O professor/tutor/preceptor intervém no processo de aprendizagem dos educandos, criando situações problematizadoras, de modo a introduzir novas informações, dando condições para que eles avancem em seus esquemas de compreensão da realidade. O educando é visto como sujeito que utiliza sua experiência e conhecimento para resolver problemas.

Na educação online (PALLOFF; PRATT, 2002, 2015; SILVA, 2006), é essencial que os indivíduos aprendam a trabalhar em grupo, de forma colaborativa, aproveitando suas capacidades intelectuais e seus conhecimentos. Os AVA aparecem como novos espaços de apoio ao trabalho docente, de forma a auxiliar no registro de informações e na troca de experiências entre professores/tutores/preceptores e educandos mediados pelas ferramentas de comunicação dispostas nesses ambientes, sendo o próprio espaço da aula nos cursos online. Permitem a inserção

Práxis Educativa, Ponta Grossa, v. 15, e2014804, p. 1-21, 2020 Disponível em: < https://www.revistas2.uepg.br/index.php/praxiseducativa> 
de referências e materiais de apoio: documentos, links, a interação, a realização de atividades; a produção colaborativa de conhecimento e a gestão: sistema, documentos e usuário.

Os AVA colocam a disposição do educando uma grande variedade de ferramentas de aprendizagem, comunicação e colaboração: $e$-mail, chat, provas de autoavaliação, bases de dados de imagens, glossário indexado, áreas de apresentação, buscas e indexação automática, sistema de anotação de páginas, qualificações acessíveis online e calendário cujas entradas podem ser editadas tanto pelo professor/tutor/preceptor como pelos educandos. Facilitam o acompanhamento do professor/tutor/preceptor em relação ao educando e ao seu desempenho na qualidade de aprendiz.

Nesses ambientes, os professores/tutores/preceptores podem acompanhar os educandos, por meio de diferentes estatísticas e resultados, que têm acesso a diferentes materiais, recursos e fontes de informação como bases de dados, programas multimídia, documentos eletrônicos, catálogos de bibliotecas, consulta a especialistas, a partir da qual constroem seu próprio conhecimento de forma autônoma, em função de suas habilidades, conhecimentos, interesses.

A aprendizagem social é um ponto importante oferecido pelas TIC e pelas redes sociais na educação online, pois permite construir valores por meio de interações coletivas em aulas online, ponto muito questionado na educação domiciliar, que não permite a socialização dos educandos. Contextos de socialização podem ser simulados com recursos de realidade virtual, com tecnologias que simulam a realidade incrementando o conhecimento, como mundos virtuais no Second Life, Open Sim e World of W arcraft. No Second Life <http://secondlife.com>, os usuários assumem seus avatares (personagens) e convivem nos mais variados espaços, que podem ser lúdicos, profissionais ou educativos, realizam transações comerciais e reais, fazem novos contatos e amizades, possibilitando criarem seus próprios objetos e programarem seus comportamentos.

Nas aulas domiciliares, são utilizados recursos do AVA, videoaulas e sala de aula invertida (flipped classroom), nos quais o professor/tutor/preceptor/pais é(são) o(s) coadjuvante(s) que trabalha $(\mathrm{m})$ ao lado dos educandos, como guia(s) da aprendizagem. A sala de aula invertida é uma modalidade de educação na qual o conteúdo e as instruções são estudados online. É um modelo que defende que os educandos realizem atividades em casa, como a leitura dos textos, a assistência dos vídeos, a produção dos materiais que o tutor/preceptor/pais necessita(m) utilizar e o educando usa para a sala de aula online ou presencial para atividades de resolução de problemas ou projetos, discussões, laboratórios etc., com o apoio do professor/tutor/preceptor e colaborativamente dos colegas, para contextualizar tudo aquilo que os educandos estudaram previamente. Para que essa proposta funcione, são necessárias uma autonomia e uma organização do educando e propostas interessantes a serem desenvolvidas pelo professor/tutor/preceptor.

O ensino híbrido (blended learning), segundo Staker e Horn (2012) e Tori (2015), combina momentos que o educando explora os conteúdos e as instruções usando TIC e outros que o ensino ocorre em uma sala de aula virtual ou presencial, podendo trocar experiências e interagir de forma socializada e colaborativa com outros educandos e com o tutor/preceptor. O conteúdo e as instruções devem ser elaborados especificamente para a disciplina em vez de usar qualquer material que o educando acessa na internet. Contam com a supervisão do professor/tutor/preceptor, que valoriza as interações interpessoais nas atividades online, de maneira a proporcionar um processo de ensino e de aprendizagem mais eficiente, interessante e personalizado.

As regras básicas para inverter a sala de aula, segundo o relatório Flipped Classroom Field Guide (2014), são: as atividades em sala de aula envolvem uma quantidade significativa de questionamentos, resolução de problemas e de outras atividades de aprendizagem ativa, obrigando o educando a recuperar, aplicar e ampliar o material aprendido online; os educandos recebem feedback imediatamente após a realização das atividades presenciais; os educandos são incentivados a 
participar das atividades online e das presenciais, sendo que elas são computadas na avaliação formal do educando; tanto o material a ser utilizado online quanto os ambientes de aprendizagem em sala de aula são altamente estruturados e bem planejados.

Os educandos podem trabalhar com os materiais no seu ritmo e tentar desenvolver o máximo de compreensão possível. São utilizadas videoaulas, às quais eles podem assistir quantas vezes forem necessárias e dedicar mais atenção aos conteúdos que apresentam maior dificuldade. Segundo Fulton (2012) e Roehl (2013), o educando avança no seu próprio ritmo; além disso, realizar as tarefas na aula faz com que os professores/tutores/preceptores observem os diferentes estilos de aprendizagem dos educandos; os professores/tutores/preceptores podem mais facilmente personalizar e atualizar os materiais disponibilizados aos educandos; permite integrar vídeos específicos sobre a matéria em estudo com gravações próprias da aula, sites da internet relacionados; possibilita aos professores/tutores/preceptores mais conhecimento relacionado à aprendizagem dos educandos, devido a maior interação educando-professor/tutor/preceptor quando eles investigam e realizam suas tarefas e maior aproveitamento das horas de presença física na aula; o apoio das TIC permite uma aprendizagem mais flexível e com novos enfoques; o educando pode dispor das conferências a qualquer momento; ajuda a criar um clima de aula mais focado na resolução de problemas nos quais o professor atua tutorizando e resolvendo dúvidas para consolidar a aprendizagem dos educandos; gera um ambiente virtual de trabalho colaborativo entre os educandos e do uso interativo das TIC, pois permite destinar à aula presencial tarefas de avaliação empírica e em resultados de aprendizagem com aplicativos específicos.

Outra possibilidade de estudo domiciliar é por meio do uso de cursos MOOC, cursos a distância que se baseiam no acesso ao conhecimento de forma aberta, tratando de chegar ao maior número de usuários possíveis com uma metodologia participativa e colaborativa. São grandes repositórios de conteúdo educacional aberto, em geral videoaulas, apostilas e outros materiais multimídia organizados na forma de cursos e costumam agregar materiais didáticos de formatos e origens diversos (TORI, 2015). Consistem em palestras e aulas de instituições de ensino e pesquisa de renome internacional transmitidas pela internet. Os cursos, em sua grande maioria, estão abertos a qualquer um que se conecte à internet e são disponibilizados por portais, em parceria com um consórcio de universidades. Alguns cursos MOOC são oferecidos por portais/plataformas como Coursera <www.coursera.org>, EDX <www.edx.org>, Udacity <www.udacity.com>, OpenUped $<$ http://www.openuped.eu>, Miríada X <https://www.miriadax.net $>$, VEduca $<$ www.veduca.com.br>, dentre outros.

É importante, também, haver exigências na legislação da educação domiciliar em relação aos mecanismos de avaliação do educando. Uma das alternativas de avaliação no contexto de TIC são as que envolvem o acompanhamento dos educandos por meio de portfólios digitais (eportfolios), que são ferramentas avaliativas que possibilitam ao tutor/preceptor uma avaliação mais ampla do processo de ensino e de aprendizagem (COUTINHO, 2010). O portfólio, usado como avaliação, provoca a reflexão, a análise do trabalho e fomenta a criação de objetivos a serem alcançados, formando, assim, educandos que sejam capazes de traçar suas próprias metas para o aprendizado, formular o seu pensamento crítico e que entendam o aprendizado como um processo.

Os e-portfolios permitem constituir registros virtuais de atividades, situações, emoções, constitui ferramenta para aprender a aprender, para auto avaliar-se; um instrumento para a reflexão, para a expressão escrita. Os portfólios ajudam na seleção da informação e da comunicação, facilitam as práticas de colaboração e de intercâmbio de experiências e o cultivo das crenças e de conhecimentos sobre a prática (MENESES; REGAÑA; MARTINEZ, 2012). O portfólio permite que os educandos registrem todo seu percurso de aprendizagem, na perspectiva de promover a autoavaliação e de estabelecer metas e objetivos para a progressão de suas aprendizagens. 


\section{Diálogo como condição inerente aos processos de ensino e de aprendizagem}

O diálogo é um processo que faz parte da constituição de todo ser humano e um procedimento inerente a todas às formas de organização cultural. Considerando, portanto, a família como um espaço privilegiado para o exercício do diálogo, este será compreendido como uma dinâmica essencial para o desenvolvimento de um projeto educativo; assim, neste caso, destaca-se a sua relevância na proposta de homeschooling.

Ao considerar, portanto, que o diálogo assume uma característica humana e, ao mesmo tempo, é identificado como uma mediação essencial do processo formativo, ele será compreendido como um atributo inerente às pessoas na significação da sua singularidade e na constituição do seu núcleo familiar, bem como uma mediação necessária e privilegiada para o desenvolvimento do processo de ensino e de aprendizagem. Tendo como referência essa abordagem, distintas aproximações poderiam ser feitas ao conceito e à prática do diálogo. Ao levar-se em conta, porém, que a demarcação dessa temática está direcionada ao homeschooling, o diálogo é proposto com base na teoria de Bakhtin (2016), que afirma que todas as linguagens humanas são, na sua essência, dialógicas. Assim sendo, acreditando que, no núcleo familiar, existem diversas linguagens, todas elas deveriam estar, de uma forma ou de outra, impregnadas dessa característica dialogal.

O diálogo, sob a abordagem instituidora da condição humana, segundo Bakhtin (2016), não traz a marca de uma individualidade, mas, sim, de várias. Nesse sentido, cada participante do núcleo familiar, que se dispõe a realizar um processo educativo, vai se transformando em um protagonista, independentemente de ser criança ou adulto. O diálogo, sob essa caracterização, constitui-se como um elemento que contribui com o respeito e o desenvolvimento das distintas individualidades do conjunto familiar.

O conjunto dessas individualidades, que caracterizam o núcleo familiar, não deveriam reforçar certo individualismo, mas, tendo como referência o reconhecimento da singularidade de cada um, estabelecer uma rede de diálogo. Tal interação entre as distintas individualidades, conforme Bakhtin (2016), revela a necessidade de intensificarem-se as relações dialógicas, principalmente por meio de processos comunicacionais passando, assim, de um diálogo convencional para um real e significativo.

Por um lado, tal configuração, segundo Bakhtin (2016, p. 122), prescinde que “[...] a relação com o interlocutor e com seu discurso é um elemento determinante do discurso no diálogo, fora do qual é impossível compreender uma réplica". Portanto, em uma proposição monológica, a réplica está ausente e, assim, não se estabelece uma relação dialógica, mas, à medida que a réplica estiver sendo incorporada, os procedimentos dialógicos começam a ter um certo sentido. Por outro lado, o diálogo como mediação educadora deveria estar pautado, segundo Bakhtin (2016), não tanto na expressão, mas muito mais na compreensão. Esse enunciado procura, justamente, romper com uma proposição mais monológica, na qual a expressão ou a explicação de um deveria ser acolhida pelos demais, para uma proposta mais dialógica, na qual a compreensão de cada um é que iria confirmar a eficácia do diálogo. Assim, o monólogo estaria vinculado à expressão e o diálogo à compreensão.

Pautar o processo educativo sobre a compreensão possibilita que cada indivíduo possa ir se configurando, não como um procedimento acumulativo de informações, mas como um processo reflexivo de troca de ideias e de pensamentos. A formação de ideias e de pensamentos ocorre, de acordo com Bakhtin (2016), na mesma proporção que ocorre um processo comunicacional; enfim, um procedimento dialogal. Segundo o autor, uma ideia ou um pensamento só se esclarece para si mesmo na medida do seu esclarecimento para o outro; daí a configuração necessária do diálogo assumir uma dimensão social.

Práxis Educativa, Ponta Grossa, v. 15, e2014804, p. 1-21, 2020 Disponível em: <https://www.revistas2.uepg.br/index.php/praxiseducativa> 
Nesse sentido, o diálogo assume a conotação de dialogicidade, isto é, existe uma intencionalidade em todo o processo dialógico. Conforme Bakhtin (2016), toda a palavra ou todo diálogo estaria sempre direcionado para alguém ou para a construção de algum sentido, seja pela abrangência individual ou social. Tal movimento, segundo o autor, precisaria incorporar, no entanto, uma dinâmica tridimensional, na qual estariam contempladas as referências dialogais com o passado (antecedente), com o presente (continuum) e com o futuro (consequente). Desse modo, o diálogo é uma dinâmica transversal dos tempos e dos espaços pessoais, familiares e sociais.

Enfim, compreender o diálogo como um elemento inerente à condição humana é uma dinâmica importante no processo de ensino e de aprendizagem. Em um contexto de homeschooling, pode contribuir com a formação individual e o empenho social de todos os envolvidos nesse núcleo familiar que, por sua vez, estaria dialogando com outros núcleos familiares, com o objetivo de significar a própria condição humana e ressignificar o processo educativo.

\section{Metodologia}

O ponto de partida deste artigo foi a pesquisa bibliográfica para a coleta de informações utilizadas na construção do guia de entrevista semiestruturada para a condução de conversas com as famílias que praticam o homeschooling. Foi utilizada a abordagem qualitativa das questões propostas para a investigação, tendo como procedimentos metodológicos a coleta de dados por meio da aplicação de um roteiro de entrevista, a descrição e a análise de resultados por intermédio da técnica de análise de conteúdo, fundamentados pelos preceitos teóricos de Bauer e Gaskell (2015).

Utilizando-se o critério de acessibilidade, optou-se pela realização de cinco entrevistas, realizadas em setembro e outubro de 2019, com as famílias que optaram pela educação domiciliar (bomeschooling), nas cidades de Brasília e Rio de Janeiro. O roteiro das entrevistas apresenta o total de dez questões construídas a respeito de como o diálogo acontece e que TIC estão presentes na educação domiciliar. O guia da entrevista incluiu três categorias:

(1) Famílias homeschooling: tempo de atuação da família na educação domiciliar; razão pela escolha do bomeschooling e benefícios percebidos na modalidade de aprendizagem.

(2) Diálogo no homeschooling: diálogo nas relações de ensino e de aprendizagem; diálogo entre as famílias bomeschooling; interações e ambientes na vida do educando desescolarizado(a).

(3) TIC no bomeschooling: que TIC são utilizadas na educação domiciliar; como essas TIC são utilizadas; se essas TIC contribuem para o processo de ensino e de aprendizagem.

De forma a manter o sigilo na identificação das famílias entrevistadas, atribuíram-se nomes hipotéticos aos entrevistados, com o intuito de preservar a identidade e a caracterização desses sujeitos. Dessa forma, precedido da letra "F", de Família homeschooling, foram definidos os nomes para os sujeitos entrevistados: F1, F2, F3, F4 e F5.

\section{Descrição e análise dos resultados}

Os procedimentos de descrição e de análise dos resultados foram desenvolvidos a partir das categorias utilizadas na construção do guia de entrevistas: Categoria 1 - As famílias homeschooling; Categoria 2 - Diálogo no homeschooling, e Categoria 3 - TIC no homeschooling. 


\section{$\checkmark$ Categoria 1 - As famílias homeschooling}

O estudo dos relatos apresentados pelas famílias entrevistadas permitiu a evidenciação de três subcategorias que identificam a relação das famílias com o bomeschooling: tempo de atuação da família no bomeschooling, razão da escolha da família pelo bomeschooling, e benefícios do bomeschooling percebidos pelas famílias.

Na primeira subcategoria, tempo de atuação da família no homeschooling, com relação ao quantitativo de anos que cada família entrevistada optou pelo homeschooling, tem-se o menor tempo - 2 anos - e o maior tempo - 27 anos, sendo o tempo médio de 12,6 anos. A Tabela 1 apresenta essa estatística por família.

Tabela 1 - Tempo de atuação da família no homeschooling

\begin{tabular}{l|l}
\hline Família & $\begin{array}{l}\text { Atuação no homeschooling } \\
\text { (anos) }\end{array}$ \\
\hline F1 & 2 \\
F2 & 27 \\
F3 & 3 \\
F4 & 6 \\
F5 & 25 \\
\hline Mínimo & 2 \\
Máximo & 27 \\
Média & 12,6 \\
\hline
\end{tabular}

Fonte: Elaborada pelos autores a partir dos dados da pesquisa. Legenda: $\mathrm{F}=$ Família.

Os anos de experiência evidenciados na Tabela 1 permitem, sob o escopo de vivência familiar com a prática do homeschooling, credenciar essas famílias como relevantes para este estudo, pois, em média, são pessoas que exercitam o homeschooling há vários anos.

$\mathrm{Na}$ segunda subcategoria, razão da escolha da família pelo homeschooling, os motivos pela escolha das famílias homeschoolers estão relacionadas às possibilidades de educação individualizada, flexibilidade para a avançar e individualizar a aprendizagem e educação especial para educandos que precisam de maior suporte. Seguem os relatos das famílias que corroboram com essa perspectiva:

Oferta de uma educação individualizada, respeitando o ritmo, a personalidade e as aptidões de cada criança. A observação de que o modelo escolar brasileiro está falido (índice de desenvolvimento da educação baixíssimo no ranking internacional). (F1).

Ensino personalizado. (F4).

Qualidade de ensino, flexibilidade para avançar e individualizar a aprendizagem [...]. (F2).

Meus filhos têm múltiplos diagnósticos, a escola ainda não é capaz de acolher, incluir verdadeiramente e buscar soluções para a educação especial e para crianças que precisem de maior suporte. Não foi uma escolha súbita, passamos por sete escolas, muitas reuniões, muita exclusão, bullying, negligência. Além disso, não estávamos satisfeitos com a educação escolarizada também sob o aspecto curricular, metodológico e didático. (F3).

[...] não tínhamos como pagar uma escola privada e nem tínhamos coragem de colocar nossa filha numa escola pública, devido ao baixo nível educacional e receios com a convivência que teriam. Conhecemos missionários de várias partes do mundo, dos Estados Unidos, Filipinas e Europa, e, por meio deles, tivemos contato com o homeschooling. Adoramos a ideia. Começamos assim, junto a outras famílias da mesma

Práxis Educativa, Ponta Grossa, v. 15, e2014804, p. 1-21, 2020 Disponível em: < https://www.revistas2.uepg.br/index.php/praxiseducativa> 
convivência, a ensinar nossos filhos em pequenos grupos, em casa. Outras questões importantes para a escolha: queríamos estar plenamente envolvidos na educação de nossas filhas, eu (mesmo tendo apenas Ensino Médio), gostava de ensinar, queríamos passar nossos valores as nossas filhas e protegê-las de ambientes negativos (palavrões, violência na escola). Queríamos oferecer a melhor educação possível a elas em nossas circunstâncias. (F5).

$\mathrm{Na}$ terceira subcategoria, as famílias foram questionadas acerca dos benefícios do homeschooling. Os relatos indicam a prática de uma educação homeschooling não fragmentada, contextualizada, que cultiva o conectar dos saberes e o amor pelo aprender:

Precisamos de menos tempo para as atividades didáticas dirigidas, já que o estudo é mais individualizado. Temos mais tempo para nos dedicar aos esportes e às aulas de música. Programamos encontros semanais com os amigos homeschoolers no parque ecológico (esses encontros duram em média 4 horas). As crianças socializam com pessoas de todas as classes sociais e idades (não só com crianças iguais a elas). Os irmãos ficam mais próximos, se ajudam, brincam e aprendem juntos e não em salas separadas. (F1).

A atitude dos filhos de serem responsáveis pelo seu progresso acadêmico, a proximidade nossa com eles, as oportunidades de passar valores e princípios, que são ainda mais essenciais e necessários para a vida do que muitos conteúdos escolares. (F2).

O principal benefício é a capacidade adaptativa do homeschooling. Poder verdadeiramente criar um ambiente de aprendizado que potencialize as habilidades dos filhos, que respeite seu tempo de aprendizagem e se preocupe com que realmente a aprendizagem aconteça, inclusive modificando recursos, método e abordagem; poder conectar saberes, dar importância e uso aos interesses, talentos e curiosidades da criança, abraçar isso e usá-los conectados ao currículo. A possibilidade de escolher um currículo, método, livros, enfim... A maior beleza do homeschooling é a liberdade de escolha e o respeito à criança. (F3).

Liberdade de escolher os conteúdos e materiais a serem usados. Cultiva o amor por aprender. É muito mais eficaz por ser personalizada. (F4).

Aprendizado individualizado, incentivo à criança pelo amor ao conhecimento, autodidatismo, adaptação aos interesses individuais da criança, menos tempo de estudos apenas sentados preenchendo livros, já que se cobre o conteúdo em menos tempo, grande facilidade para fazermos excursões, ir a parques, feiras, exposições, museus, etc. Minhas filhas cresceram sempre fazendo muitas excursões e conheceram desde a fábrica da Embrapa a Fiocruz. Íamos frequentemente ao Teatro Municipal, Centro Cultural Banco do Brasil (CCBB), tiveram o privilégio de conhecer o Museu Nacional, além de muitas atividades ao ar livre, trilhas, etc. No bomeschooling, tudo e oportunidade de aprendizado, não se separa na cabeça da criança, "isso é matéria da escola", "isso é conversa fora da escola". (F5).

Ambas aprenderam a ler com facilidade (mesmo sem eu ser professora formada, inclusive a mais nova foi alfabetizada por uma jovem de 18 anos sem escolarização formal, e por sua irmã de 15). Uma vez capazes de ler, e tendo sido incentivadas a tal, liam com frequência e meu trabalho era mais selecionar e oferecer boas leituras a elas. Tivemos muita convivência enquanto família. Quando queríamos tirar uma semana de folga, não precisava ser durante as férias escolares. Quando ficavam doentes, isso não atrapalhava os estudos tampouco. Foi uma experiência ótima. Como ensinei junto a outras famílias, isso também facilitou para nós, pois nos dividíamos. Quando ficaram maiores e havia conteúdos que não conseguíamos ensinar, contratamos tutores. Gastávamos muito pouco dinheiro também! (F5).

Os relatos das famílias mostram os benefícios indicados pelas famílias que praticam o homeschooling: menos tempo para as atividades didáticas dirigidas; socialização das crianças e dos adolescentes com pessoas de todas as classes sociais e idades; atitude dos filhos de serem responsáveis pelo seu progresso acadêmico; oportunidades de passar valores e princípios familiares,

Práxis Educativa, Ponta Grossa, v. 15, e2014804, p. 1-21, 2020

Disponível em: <https://www.revistas2.uepg.br/index.php/praxiseducativa> 
de potencializar as habilidades dos filhos; conectar saberes; além da flexibilidade de escolher um currículo, método e livro didático.

\section{$\checkmark$ Categoria 2 - Diálogo no homeschooling}

Os relatos apresentados pelos professores entrevistados evidenciaram três subcategorias para o estudo das relações e das interações do diálogo na prática do homeschooling: o diálogo nas relações de ensino e de aprendizagem; o diálogo entre as famílias homeschooling; e as interações e os ambientes na vida da criança/do adolescente desescolarizada(o).

$\mathrm{Na}$ primeira subcategoria, o diálogo na relações de ensino e de aprendizagem, as famílias homeschoolers reconhecem o diálogo como uma prática essencial para os processos de ensino e de aprendizagem, que deve ocorrer em todos os momentos e espaços, inclusive nas atividades diárias, em uma relação familiar, em que o responsável pela aprendizagem exerça uma escuta sensível do educando-filho, seja aberto e flexível, de modo a promover oportunidades de diálogo e respeitar seus saberes e suas dificuldades, conforme os relatos a seguir:

O diálogo é essencial. Sem ele seria impossível praticar a educação domiciliar. Ele deve acontecer em todos os momentos e espaços, inclusive nas atividades diárias, como durante o ato de preparar um alimento, por exemplo (a criança aprende formas de medidas, operações matemáticas, propriedades da química e da física) ou no trajeto para um passeio (conversando sobre o funcionamento e as leis de trânsito). (F1).

Desde o planejamento, como na escolha de materiais, horário, estrutura. O diálogo acontece oficial e naturalmente. E necessário avaliar-se e escutar o aluno-filho, ser aberto e flexível sempre. (F2).

O diálogo se estabelece como processo no bomeschooling desde o momento inicial, já que é uma decisão familiar, passa pela escolha de materiais que melhor se adaptem àquela criança, respeitando seus saberes e suas dificuldades. A avaliação geralmente é um processo contínuo e gradativo, possibilitando maior autonomia e encorajamento, o que reflete em avanços nas habilidades socioemocionais da criança homeschooler. Além disso, as crianças educadas em casa não vivem apartadas da sociedade, pelo contrário, estão inseridas nela e fazem parte de vários grupos sociais. (F3).

$\mathrm{Na}$ maioria das cidades brasileiras, já existem grupos de apoio em que as famílias partilham experiências e se reúnem para atividades educativas, culturais e esportivas. As crianças geralmente praticam esportes e/ou fazem cursos livres ou de idiomas, têm amigos, frequentam parques, bibliotecas, clubes, igrejas e demais ambientes onde há trocas sociais. Aliás, cabe ressaltar que muitas vezes a criança homeschooler tem até mais contato com o "diferente" do que a escolarizada. Em nossos grupos de apoio, por exemplo, temos famílias de todas as faixas de renda, de diferentes religiões, crianças de todas as idades e algumas com diagnósticos que exigem um pouco mais de estratégias de inclusão eficaz. (F3).

Algumas crianças participam de comunidades de aprendizagem em que há reuniões regulares e elas aprendem juntas e tem tutor, outras famílias optam por outras formas de criar e aprender coletivamente. Mas o que tenho visto e aprendido nestes três anos é que as famílias não só promovem oportunidades de diálogo e troca como anseiam por isso. Um grande entrave ao maior engajamento e possibilidade de diálogo mais amplo com a sociedade é justamente a falta de regulamentação da educação domiciliar, o que nos coloca numa posição um pouco desconfortável e sujeitos a perseguição estatal. Há ainda, no Brasil, um longo caminho a ser percorrido quando falamos sobre democracia e suas possibilidades, ainda mais quanto à temática da educação. A educação domiciliar deve ser encarada como uma possibilidade a mais, democrática e prevista pelos tratados internacionais de direitos humanos aos quais o nosso país se tornou signatário. (F3).

Práxis Educativa, Ponta Grossa, v. 15, e2014804, p. 1-21, 2020 Disponível em: <https://www.revistas2.uepg.br/index.php/praxiseducativa> 
Amplo e diverso. Não se restringe a um determinado professor e ao nivelamento por idade. As crianças educadas em casa são muito mais socializadas, convivem e conversam com pessoas de todas as idades e locais. (F4).

E uma convivência familiar que, nos momentos determinados, se transforma em momentos de estudo. Como minhas filhas não frequentaram uma escola quando eram pequenas, essa forma de aprender era muito natural para elas. (F5).

$\mathrm{Na}$ segunda subcategoria - diálogo entre as famílias homeschooling -, as respostas das famílias indicam que o diálogo ocorre naturalmente entre as famílias nos diferentes ambientes e meios, promovendo a integração e a interação entre os envolvidos nas práticas de homeschooling. Com relação aos meios utilizados para a realização dos diálogos, têm-se as redes sociais, os eventos, os congressos, os cursos para pais educadores, as oficinas para as crianças e adolescentes etc. A seguir, são apresentados os relatos das famílias:

Nesses tempos modernos, o diálogo entre famílias acontece principalmente por meio das redes sociais. Há também uma agenda de encontros semanais, quinzenais e mensais entre os diversos grupos de famílias. (F1).

Pratiquei o homeschooling tipo "cooperativo" com famílias de estrangeiros em Brasília e no Rio, em uma época sem blogs ou muita internet. Tínhamos reuniões regulares e até seminários prolongados. A troca e o apoio eram constantes. (F2).

[...] as famílias estão inseridas na sociedade e como tais, exercem diálogo no seu cotidiano, nos diferentes ambientes e meios em que interagem e entre si também. Há muitos grupos de apoio para famílias educadoras, cada vez mais organizados e crescendo. Além dos contatos mais próximos, há também forte interação através de outros meios que possibilitam essa comunicação, como as redes sociais, eventos, congressos, cursos para pais educadores, oficinas para crianças, etc. Enfim, como a educação domiciliar vem crescendo muito em nosso país nos últimos anos, as possibilidades de interação, diálogo e trocas vem acompanhando esse crescimento. (F3).

Participamos ativamente de grupos de apoio de famílias educadoras, frequentamos parques, igreja, museus, eventos sociais. O diálogo não é algo restrito. Além do que o ensino personalizado permite de fato ouvir as crianças, enquanto na escola isso se mantém restrito e rígido. (F4).

[...] a forma de dialogar das famílias era também a forma de dialogar durante os estudos. Famílias que não querem dialogar com seus filhos provavelmente não vão querer fazer bomeschooling. (F5).

$\mathrm{Na}$ terceira subcategoria, sobre as interações e os ambientes na vida da criança/do adolescente desescolarizada(o), as famílias destacam que as crianças e os adolescentes do bomeschooling são naturalmente curiosas(os) e de fácil interação com as pessoas de todas as idades e todos os níveis sociais. Os relatos das famílias homeschoolers são apresentados a seguir:

A criança desescolarizada interage especialmente nos ambientes da vida real. Ela acompanha seus pais (especialmente sua mãe) em todo o seu dia a dia, nos momentos em que não está realizando um estudo formal. Quando desce para brincar embaixo do prédio, dialoga com o porteiro, o zelador, os vizinhos, o entregador de gás, o coletor de lixo. Quando vai ao mercado ou à padaria, dialoga com os atendentes, faz o cálculo do troco, lê os cartazes e faz o próprio pedido. Quando vai às aulas de ginástica, natação, música, libras, dialoga com os professores e os mais diferentes alunos. Quando vai ao parquinho ou à igreja, dialoga com outras crianças (escolarizadas ou não), aprendendo coisas novas e ensinando também. Na rua, no dia a dia, tem contato com diferentes profissionais exercendo ao vivo suas profissões, suprindo, assim, suas curiosidades em relação ao funcionamento real do mundo. (F1).

Sou filha de professores, e algo que eles observaram foi o quanto as crianças e jovens do homeschooling são naturalmente curiosos e de fácil interação com pessoas de todas as idades

Práxis Educativa, Ponta Grossa, v. 15, e2014804, p. 1-21, 2020

Disponível em: <https://www.revistas2.uepg.br/index.php/praxiseducativa> 
e níveis sociais. O "adulto" como figura de autoridade, não é seu "inimigo", os seus iguais não são "competidores". O diálogo se torna fonte de troca e enriquecimento. (F2).

Citando apenas minha experiência pessoal: em sete escolas diferentes meus filhos sofreram com muitas situações de preconceito, negligência, bullying, violência, exclusão, falta de socialização, ansiedade etc. Hoje, três anos após iniciarmos o bomeschooling, tiveram alta da fonoaudióloga e o psicólogo passou a acompanhar apenas trimestralmente, antes sendo duas sessões por semana. Meus filhos hoje têm amigos diversos, entre eles crianças homeschoolers e escolarizadas, praticam esporte, não têm mais transtorno de ansiedade e depressão, conseguiram alcançar avanços significativos nas habilidades sociais e emocionais. Eu posso garantir que hoje eles estão muito mais integrados socialmente, desenvolveram habilidades sociais e emocionais, capacidade de respeitar as diferenças e também de exercer atitudes de empatia e de ajuda ao outro. (F3).

Toda habilidade que se exerce socialmente interfere diretamente em como essa criança age, interage e internaliza nas suas trocas sociais. Então, basicamente, o que tenho visto entre as crianças desescolarizadas é uma maior capacidade de conviver e respeitar o diferente, porque os grupos de educação domiciliar são muito diversos em vários quesitos e porque elas também interagem e vivenciam uma abrangência maior de espaços sociais. Como a rotina é adaptável e a tendência é que a educação personalizada alcance resultados esperados em menor fração de tempo que a escolar, os homeschoolers tem, via de regra, mais tempo livre e costumam participar de muitas atividades fora de casa. (F3).

A criança educada em casa está inserida na sociedade. Na família, ela já tem uma qualidade de diálogo muito mais eficiente pois tem contato com pessoas mais novas (desde bebês) até pessoas de idade. E isso com naturalidade. Essa criança não precisa de seus pares para dialogar, ela aprende a dialogar com todos e de forma respeitosa, olho no olho e não digital. Isso sim é um diálogo saudável. Se a criança tem uma dúvida, ela logo é respondida, não existe vergonha em perguntar. Se a criança já aprendeu algo, novo conteúdo é então apresentado. É muito mais eficaz, fácil e natural. O aprendizado acontece o tempo todo e as crianças têm sede por aprender. (F4).

$\mathrm{Na}$ escolha dos estudos, na negociação dos termos do estudo (criança que estuda em casa também pode preferir brincar a se sentar para estudar), nas escolhas de atividades extracurriculares, na hora da escuta dos pais sobre dificuldades nos estudos (por exemplo, descobrir porque um certo conteúdo esta sendo chato para a criança) etc. (F5).

As famílias responderam que as interações proporcionadas pelos diálogos acontecem no dia a dia das crianças e dos adolescentes, a exemplo de conversas com o porteiro do prédio, zelador, vizinhos, entregador de gás, coletor de lixo, com os atendentes da padaria, com os professores nas aulas de ginástica, natação, música, libras, com outras crianças e adolescentes (escolarizadas ou não).

\section{$\checkmark$ Categoria 3 - TIC no homeschooling}

Os relatos apresentados pelas famílias entrevistadas apresentam três subcategorias que identificam as ferramentas TIC utilizadas, a maneira em que são utilizadas e suas contribuições para o bomeschooling. Na primeira subcategoria, as TIC utilizadas no bomeschooling, as famílias responderam que as ferramentas de TIC utilizadas no bomeschooling são as redes sociais, sites de pesquisas, plataformas educativas, aplicativos, internet e cursos online, entre outros. As famílias homeschoolers apresentam relatos que corroboram essa afirmativa:

Redes sociais (WhatsApp, Facebook, Instagram), sites de pesquisa, plataformas de aprendizagem. (F1).

[...] jogos de computador educativos. Acho que para complementar o ensino. O importante é pesquisar e achar qualidade. (F2).

Práxis Educativa, Ponta Grossa, v. 15, e2014804, p. 1-21, 2020

Disponível em: <https://www.revistas2.uepg.br/index.php/praxiseducativa> 
Uma das críticas que faço à educação escolarizada é justamente o distanciamento entre a sala de aula e todas as possibilidades de aprendizagem que a tecnologia pode ofertar. Usamos variados instrumentos tecnológicos, como: plataformas educativas como K12, Khan Academy, IXL, Headsprout e Raz-kids; videoaulas, pesquisas online e in loco; jogos educativos, cursos online; conferências, congressos e reuniões por meio de plataformas online, etc. As possibilidades são infinitas. Vão desde aprender sobre cartografia usando recursos como o Google Earth, como fazer um clube literário ou de trocas de caixas de natureza com outras crianças de diferentes regiões do país. Eu creio que as crianças desescolarizadas estão fazendo bom uso das tecnologias em sua educação. Ouso dizer que usam esses recursos muitíssimo mais do que as escolas e sabendo fazer bom uso deles. (F3).

Usamos aplicativos (de matemática, por exemplo), internet é uma grande ferramenta de apoio no preparo das aulas, seja em busca de conteúdo ou mesmo de locais onde iremos aprender ou aprofundar determinado assunto ou conteúdo. Fazemos cursos com professores online também, seja para os pais se capacitarem ou uma determinada tutoria. As possibilidades são infinitas. (F4).

$\mathrm{Na}$ minha primeira filha, apenas começava-se a ter acesso a computadores. Ela brincava com alguns jogos, aprendeu a digitação, e fazia alguns jogos de matemática, língua, spelling no computador, conforme iam sendo produzidos. Utilizava também vídeos, filmes e música. A segunda filha, nascida em 1997, já teve acesso à internet. Baixava muitos exercícios, temas, etc. da internet para estudarmos. (F5).

Muitas vezes escolhíamos um tema, e elas pesquisavam na internet. Foram ensinadas a identificar informações duvidosas, inclusive questionar Wikipédia, etc. e a começar a identificar ideologias por detrás dos textos. Ambas gostavam de jogar no computador (às vezes até demais). Minha primeira filha aprendeu Design Gráfico sozinha e resolveu mais tarde, fazer faculdade nesta área. A segunda, escolheu o curso de Computação. No meu caso, a internet facilitou muito o nosso trabalho. Usamos livros textos e de exercícios, mas era muito fácil buscar na internet qualquer complemento que queríamos. Alguns assuntos eram estudados só na internet. Logo adotei alguns sites educativos. Com o tempo, apareceram também as videoaulas. (F5).

$\mathrm{Na}$ segunda subcategoria, como as TIC são utilizadas no homeschooling, as famílias homeschoolers responderam que são utilizadas principalmente para estudo de idiomas, cursos online, livros digitais, tours virtuais, videoaulas, serviços de streaming, pesquisa em sites, entre outros. A seguir, são apresentados os relatos das famílias:

As tecnologias são utilizadas especialmente pelos pais no processo de preparo de conteúdo e no planejamento de aulas e encontro de famílias. Evitamos que as crianças as utilizem em excesso. (F1).

Para complementar e realçar conteúdos, para pesquisa, mas nunca como única fonte de informação. (F2).

Na fixação de conteúdo, no aprendizado e na avaliação. (F4).

As crianças desescolarizadas utilizam uma diversidade de meios para aprenderem. Como exemplo, citarei nosso caso: usamos plataformas educativas (algumas pagas, outras gratuitas, mas mesmo as pagas o custo é baixo comparado a um livro didático, por exemplo. Então, a licença anual de uma delas, comprada por meio de um grupo grande de famílias educadoras, sai em torno de R\$100,00 anuais, ou seja, menos de R \$10,00 por mês!), usamos aplicativos principalmente para estudo de idiomas, também temos matrícula em dois cursos online mas com aulas ao vivo e interação entre os professores e as crianças (um deles de Literatura para Crianças e outro de Robótica e Eletrônica para crianças), usamos também alguns aplicativos, videoaulas, serviços de streaming, pesquisa em sites e tours virtuais. Recentemente também passamos a usar livros digitais e o Kindle, pelo custo mais baixo e praticidade. Enfim, são muitas formas de usar a tecnologia e tudo o que ela nos oferece em prol da educação de nossos filhos. (F3).

Práxis Educativa, Ponta Grossa, v. 15, e2014804, p. 1-21, 2020

Disponível em: < https://www.revistas2.uepg.br/index.php/praxiseducativa> 
Acho que de forma mais livre e com frequência bem maior. Fica a critério dos pais também, é claro. Mas dentre as famílias que conheço, a maioria utiliza amplamente as tecnologias. (F5).

$\mathrm{Na}$ terceira subcategoria, sobre as contribuições da TIC no homeschooling, as famílias alertam que o uso das TIC deve ser precedido de avaliação, de um processo de seleção, que garanta aos educandos-filhos proteção quanto ao uso excessivo de telas e de livre navegação, conforme mostram os relatos a seguir:

Atualmente, há um mundo a ser descoberto por meio dessas ferramentas. A informação está cada vez mais disponível para cada vez mais pessoas. As possibilidades de contribuição são inúmeras: e-books com bons conteúdos, aplicativos educativos, plataformas de aprendizado (utilizamos uma para língua estrangeira), tutoria a distância etc. (F1).

Como ferramentas de apoio. (F4).

De forma simples e pragmática, contribuem para que haja momentos que a criança estuda sozinha. Mas há necessidade dessas ferramentas serem avaliadas e bem selecionadas. Não serem utilizados como uma muleta, ou algo para preencher o tempo. (F2).

É insano educar uma criança hoje sem estar atento e usando muitas ferramentas que a tecnologia nos possibilita. Se o mundo está cada vez mais tecnológico e a educação tem como fim possibilitar a uma criança se desenvolver plenamente, a tecnologia deve ser usada como aliada. Importante apenas estarmos atentos para uma proteção quanto ao uso excessivo de telas e livre navegação, por isso poder acarretar danos às nossas crianças, mas de forma consciente e segura, a tecnologia só tem a acrescentar diversidade e caminhos novos à educação. $\mathrm{O}$ uso dela possibilita uma amplitude maior de conhecimento e conexão entre diferentes áreas de saberes, ajudando a pensar de forma mais contextualizada e integrada, dando uma abordagem multidisciplinar a muitos conteúdos. (F3).

A criança homeschooler tende ao autodidatismo. $\mathrm{O}$ acesso à internet permite ao aluno pesquisar qualquer assunto que the interesse. A quantidade deste acesso vai ser de acordo com o critério e o planejamento de cada família. Com certeza, de acordo com a faixa etária também. Homeschooling trata-se de liberdade para aprender. As tecnologias facilitam este trabalho, mas decidir como serão usadas ou por quanto tempo é uma questão individual, da família. Como ambas minhas filhas seguiram por áreas profissionais ligadas à tecnologia, posso dizer, pela minha experiência, que tiveram acesso pleno, se desenvolveram nas tecnologias sem minha ajuda (não sou da geração da internet) e até escolheram caminhos profissionais na área. (F5).

As famílias homeschoolers indicam que as TIC facilitam os processos de ensino e de aprendizagem, permitem ao educando pesquisar qualquer assunto que lhe interesse, contribuem para o estudo autônomo de crianças e de adolescentes, de modo a possibilitar uma amplitude maior de conhecimento e de conexão entre diversas áreas dos saberes, ajudar a pensar de forma contextualizada e integrada, em uma abordagem multidisciplinar.

\section{Considerações finais}

O objetivo deste artigo foi de caracterizar o homeschooling e identificar as contribuições das TIC na educação domiciliar no desenvolvimento de competências dialógicas na formação dos educandos e pais que vivenciam essa modalidade educacional. Os achados da pesquisa realizada com as famílias homeschoolers evidenciaram a importância do diálogo e das TIC como instrumentos que ampliam as possibilidades de aprendizagem de crianças e de adolescentes homeschoolers. 
A educação individualizada, flexibilidade para a avançar e individualizar a aprendizagem e educação especial para educandos que precisam de maior suporte são as principais razões pela escolha do bomeschooling. Há o reconhecimento das famílias que a prática do bomeschooling permite, de forma não fragmentada e contextualizada, a conexão entre os saberes. Essas famílias indicam que a prática do homeschooling traz como benefícios menos tempo de atividades didáticas, a socialização das crianças e dos adolescentes, que são naturalmente curiosos, com pessoas de todas as classes sociais e idades, entre outros.

As famílias homeschoolers compreendem o diálogo como uma prática essencial aos processos de ensino e de aprendizagem que deve ocorrer em todos os momentos e espaços, inclusive nas atividades diárias, de forma natural, entre as famílias bomeschooling, de forma a integrar e interagir todos os envolvidos nessa prática. Nesse sentido, os meios utilizados para a realização dos diálogos envolvem redes sociais, eventos, congressos, cursos para pais educadores, oficinas para os educandos. As ferramentas de TIC utilizadas no bomeschooling são as redes sociais, sites de pesquisas, plataformas educativas, aplicativos, internet e cursos online, principalmente para o estudo de idiomas, cursos online, livros digitais, tours virtuais, videoaulas, serviços de streaming, pesquisa em sites, entre outros. Além disso, as famílias praticantes do homeschooling destacam que as TIC facilitam os processos de ensino e de aprendizagem, contribuindo para o estudo autônomo de educandos, possibilitando uma amplitude maior de conhecimento e de conexões entre os saberes.

Com esses resultados, é possível inferir que a prática do homeschooling, mediada pelo diálogo e pelas TIC, pode favorecer a atribuição de sentido e de significado para os educandos, permitindo uma maior efetividade na aprendizagem bomeschooling deles. Como limitação desta pesquisa, tem-se a quantidade de famílias que participaram deste estudo. Contudo, os resultados aqui detalhados poderão ser comprovados em estudos posteriores, em possível ampliação dos sujeitos da pesquisa.

\section{Referências}

AGUIAR, A. M. F. M. A situação jurídica do ensino domiciliar no Brasil. Revista Jus Navigandi, Teresina, ano 16, n. 2929, jul. 2011. Disponível em: <https://jus.com.br/artigos/19514/asituacao-juridica-do-ensino-domiciliar-no-brasil>. Acesso em: 5 set. 2019.

ANDRADE, E. P. A educação familiar desescolarizada como um Direito da Criança e do Adolescente: relevância, limites e possibilidades na ampliação do Direito à Educação. 2014. 552 f. Tese (Doutorado em Educação) - Faculdade de Educação da Universidade de São Paulo, São Paulo, 2014.

ANDRADE, E. P. Educação domiciliar: encontrando o Direito. Pro-posições, Campinas, v. 28, n. 2, p. 172-192, maio./ago. 2017. DOI: https://doi.org/10.1590/1980-6248-2016-0062

ANED. Associação Nacional de Educação Domiciliar. ED no Brasil. Brasília: Distrito Federal, 2019. Disponível em: <https://www.aned.org.br/conheca/ed-no-brasil>. Acesso em: 5 set. 2019.

AURINI, J.; DAVIES, S. Choice without markers: homeschooling in context of private education. British Journal of Sociology of Education, v. 26, n. 4, p. 461-474, set. 2005. DOI: https://doi.org/10.1080/01425690500199834

BAKHTIN, M. Os gêneros do discurso. São Paulo: Editora 34, 2016. 
BARBOSA, L. M. R. Ensino em casa no Brasil: um desfio à escola? 2014. 350 f. Tese (Doutorado em Educação) - Faculdade de Educação da Universidade de São Paulo, São Paulo, 2013.

BARBOSA, L. M. R. Homeschooling no Brasil: ampliação do direito à educação ou via de privatização? Educação \& Sociedade, Campinas, v. 37, n. 134, p. 153-168, jan./mar. 2016. DOI: https://doi.org/10.1590/ES0101-73302016157215

BARBOSA, L. M. R.; EVANGELISTA, N. S. Educação domiciliar e direito à educação: a influência norte-americana no Brasil. Educação em Perspectiva, Viçosa, v. 8, n. 3, p. 328-344, set./dez. 2017. DOI: https://doi.org/10.22294/eduper/ppge/ufv.v8i3.907

BAUER, M. W.; GASKELL, G. (Orgs.). Pesquisa qualitativa com texto, imagem e som: um manual prático. Petrópolis: Vozes, 2015.

BRASIL. Lei $\mathbf{N}^{\circ}$ 9.394, de 20 de dezembro de 1996. Estabelece as diretrizes e bases da educação nacional. Brasília: Presidência da República, Casa Civil, Subchefia para Assuntos Jurídicos, [1996]. Disponível em: <http://www.planalto.gov.br/ccivil_03/leis/19394.htm>. Acesso em: 10 nov. 2019.

BRASIL. Decreto $\mathbf{N}^{\circ}$ 5.622, de 19 de dezembro de 2005. Regulamenta o Art. 80 da Lei no 9.394, de 20 de dezembro de 1996. Brasília: Presidência da República, Casa Civil, Subchefia para Assuntos Jurídicos, [2005]. Disponível em: <https://www2.camara.leg.br/legin/fed/decret/2005/decreto5622-19-dezembro-2005-539654-publicacaooriginal-39018-pe.html>. Acesso em: 12 dez. 2019.

BRASIL. Decreto $\mathbf{N}^{\circ}$ 9.057, de 25 de maio de 2017. Regulamenta o art. 80 da Lei no 9.394, de 20 de dezembro de 1996, que estabelece as diretrizes e bases da educação nacional. Brasília: Presidência da República, Secretaria-Geral, Subchefia para Assuntos Jurídicos, [2005]. Disponível em: $<$ https://www.in.gov.br/materia//asset_publisher/Kujrw0TZC2Mb/content/id/20238603/do1-2017-05-26-decreto-n-9-057-de25-de-maio-de-2017-20238503 >. Acesso em: 13 nov. 2019.

BRASIL. Lei $N^{o}$ 8.069, de 13 de julho de 1990. Dispõe sobre o Estatuto da Criança e do Adolescente e dá outras providências. Diário Oficial da União: seção 1, Brasilia, DF, n. 135, p. 13563, 16 jul. 1990.

COLL, C.; MONEREO, C. (Orgs.). Psicologia da educação virtual: Aprender e ensinar com as tecnologias de informação e comunicação. Porto Alegre: Artmed, 2010.

COSTA, V. F. Homeschooling no Brasil: uma análise da constitucionalidade da legalidade do projeto de lei 3179/12. Belo Horizonte: D’Plácido, 2016.

COUTINHO, C. P. Challenges for teacher education in the learning society: case studies of promising practice. In: YANG, K. H.; YUEN, S. C. (Orgs.). Handbook of research on practices and outcomes in e-learning: issues and Trends. Hershey: IGI Global, 2010. p. 385-401.

CURY, C. J. Homeschooling ou educação no lar. Educação em Revista, Belo Horizonte, v. 35, p. 1-8, jul. 2019. DOI: https://doi.org/10.1590/0102-4698219798 
DAVIES, S.; AURINI, J. Homeschooling and Canadian educational politics: rights, pluralism and pedagogical individualism. Evaluation \& Research in Education, v. 17, n. 2, p. 63-73, maio 2003. DOI: $\underline{\text { https://doi.org/10.1080/09500790308668292 }}$

DUMAS, T. K.; GATES, S.; SCHWARZER, D. R. Evidence for homeschooling: constitutional analysis in light of Social Science research. Widener Law Review, Wilmington, v. 16, n. 1, p. 63$87,2010$.

FLIPPED Classroom Field Guide. Flipped Classroom Field Guide. 2014. Disponível em: <https://tlc.uic.edu/files/2016/02/Flipped-Classroom-Field-Guide.pdf>. Acesso em: 19 nov. 2019.

FULTON, K. Upside down and inside out: flip your classroom to improve student learning. Learning \& Leading with Technology, Virginia, v. 39, n. 8, p. 12-17, jun./jul. 2012.

FUNDACIÓN TELEFÓNICA. Aprender con tecnologias: investigación internacional modelos educativos Del futuro. Madrid: Fundación Telefonica/Ariel, 2012.

GHEC. Global Home Education Exchange. Global Home Education Conference. 2016. Disponível em: <https://ghex.world/conferences/ghec-2016>. Acesso em: 5 set. 2019.

HARASIM, L. et al. Redes de aprendizagem: um guia para ensino e aprendizagem on-line. São Paulo: Editora Senac São Paulo, 2005.

JONASSEN, D. H. et al. Cognitive flexibility hypertexts on the web: engaging learners in making meaning. England: Khan, 1997.

KUNZMAN, R. Education, schooling and children's rights: the complexity of homeschooling education theory. Educational Theory, Illinois, v. 62, n. 1, p. 75-89, fev. 2012. DOI: https://doi.org/10.1111/j.1741-5446.2011.00436.x

MENESES, E. L.; REGAÑA, C. B; MARTINEZ, A. J. Los portafolios digitales como recursos didácticos para la innovación docente. In: ROMERO, Y. S. et al. (Orgs.). Las tecnologías de la información en contextos educativos: nuevos escenarios de aprendizaje. Santiago de Cali: Universidad Santiago de Cali, 2012. p. 241-269.

MONEREO, C.; POZO, J. J. O aluno em ambientes virtuais: condições, perfil e competências. In: COLL, C.; MONEREO, C. (Orgs.). Psicologia da educação virtual: aprender e ensinar com as tecnologias da informação e comunicação. Porto Alegre: Artmed, 2010. p. 97-117.

MORAES, M. C. O paradigma educacional emergente. Campinas: Papirus, 1997.

NEVES JÚNIOR, I. J. Possibilidades educativas no exercício da dialogicidade. In: SÍVERES, L.; VASCONCELOS, I. C. (Orgs.). O. Diálogo: um processo educativo. Brasília: Cidade Gráfica Editora, 2018. p. 51-66.

NEW MEDIA CONSORTIUM. NMC Horizon Report: Higher Education Edition 2013. Austin, Texas: New Media Consortium, 2013. 
NOVAES, S. et al. Homeschooling no Brasil: um estudo sobre as contribuições do ensino domiciliar no desenvolvimento das competências individuais e na formação educacional. In: SIMPÓSIO INTERNACIONAL DE GESTÃO DE PROJETOS, INOVAÇÃO E SUSTENTABILIDADE, 6., São Paulo. Anais [...]. São Paulo: UNINOVE, 2017. p. 1-15.

PALLOFF, R.; PRATT, K. Construindo comunidades de aprendizagem no ciberespaço: estratégias eficientes para salas de aulas on-line. Porto Alegre: Artmed, 2002.

PALLOFF, R.; PRATT, K. Lições da sala de aula virtual: as realidades do ensino on-line. Porto Alegre: Penso, 2015.

PÉREZ GÓMEZ, Á. I. Educação na era digital: a escola educativa. Porto Alegre: Artmed, 2015.

PICOLI, B. A. Homeschooling e os irrenunciáveis perigos da educação: reflexões sobre as possibilidades de educação sem escola no mundo plural a partir de Arendt, Biesta e Savater. Práxis Educativa, Ponta Grossa, v. 15, e2014535, p. 1-22, 2020. DOI: https://dx.doi.org/10.5212/PraxEduc.v.15.14535.023

ROEHL, A. Bridging the field trip gap: integrating web-based video as teaching and learning partner in interior design education. Journal of Family \& Consumer Sciences, Virginia, v. 105, n.1, p. 42-46, 2013. DOI: https://doi.org/10.14307/JFCS105.1.9

SÃO JOSÉ, F. M. O homeschooling sob a ótica do melhor interesse da criança e do adolescente. Belo Horizonte: Del Rey, 2014.

SEMIS, L. Homeschooling: 14 perguntas e respostas. Nova Escola, 11 fev. 2019. Disponível em: <https://novaescola.org.br/conteudo/15636/homeschooling-14-perguntas-erespostas>. Acesso em: 5 set. 2019.

SILVA, M. (org.) Educação online: teorias, práticas, legislação e formação corporativa. 2. ed. São Paulo: Loyola, 2006.

STAKER, H.; HORN, M. B. Classifying K-12 blended learning. Mountain View: Innosight Institute, Inc. 2012.

TORI, R. Uso das novas tecnologias em cursos on-line. In: KENSKI, V. M. (org.). Design instrucional para cursos online. São Paulo: Senac, 2015. p. 59-89.

VASCONCELOS, M. C. C. A educação de crianças e jovens na casa: aspectos da legislação no Brasil e em Portugal. In: CONGRESSO BRASILEIRO DE HISTÓRIA DA EDUCAÇÃO, 8., 2015, Maringá. Anais [...]. Maringá: UEM, 2015. p. 94-95.

VIEIRA, A. de H. P. Escola? Não, obrigado: um retrato da homeschooling no Brasil. 2012. 76 f. Trabalho de Conclusão de Curso (Graduação em Ciências Sociais) - Universidade de Brasília, Brasilia, 2012.

Recebido em 05/01/2020

Versão corrigida recebida em 23/02/2020

Aceito em 24/02/2020

Publicado online em 09/03/2020

Práxis Educativa, Ponta Grossa, v. 15, e2014804, p. 1-21, 2020 Disponível em: <https://www.revistas2.uepg.br/index.php/praxiseducativa> 